\title{
Adjuvant Therapy in Pancreatic Cancer
}

\section{Abstract}

Adjuvant treatment following curative resection for pancreatic cancer is now well established. Historically, the role of adjuvant therapy post resection was uncertain, as was the best form of adjuvant, the choices lying between adjuvant chemotherapy, chemoradiation or a combination of these. The landmark randomized controlled European Study Group for Pancreatic Cancer (ESPAC)-1 trial, provided the strongest evidence for the benefit of adjuvant therapy. ESPAC-1 showed a strong survival advantage for chemotherapy comprising 5-fluorouracil (5-FU) with folinic acid (FA), but no support for the use of chemoradiation. The CONKO-001 trial showed that gemcitabine was also superior to surgery alone. The ESPAC-3 trial showed no superiority for gemcitabine over 5-FU/FA although gemcitabine was less toxic. The effects of adding biological agents or combining agents within regimens are being investigated as well as neo-adjuvant therapies being compared with adjuvant therapy. A network meta-analysis has confirmed reduced survival and increased toxicity with adjuvant chemoradiotherapy. Adjuvant systemic chemotherapy with either gemcitabine or 5-FU/FA following curative resection for pancreatic adenocarcinoma continues as the mainstay of treatment. The five-year survival rates are around $25 \%$ with chemotherapy compared to resection alone, with a significant survival benefit also shown for patients with $\mathrm{R} 1$ positive resection margins.

Key Words: Adjuvant therapy; Pancreatic cancer; ESPAC

Non Standard Abbreviations: 5-FU: 5-Fluorouracil; FA: Folinic acid; EBRTexternal bean radiotherapy; EORTC: European Organization for Research and Treatment of Cancer; ESPAC: European Study Group for Pancreatic Cancer; HENT1: Human equilibrative nucleoside transporter 1; RTOG: Radiation Therapy Oncology Group

\section{Frances Oldfield ${ }^{1}$, Paulla Ghaneh ${ }^{1,2}$, Richard Jackson ${ }^{2}$, Christopher Halloran ${ }^{1}$}

\section{National Institutes of Health Research Liverpool Pancreas Biomedical Research Unit and Clinical Directorate of General Surgery, Royal Liverpool and Broadgreen University Hospitals NHS Trust and the University of Liverpool, Liverpool L69 3GA, UK. \\ 2 Cancer Research UK Liverpool Cancer Trials Unit, University of Liverpool, Block C Waterhouse Building, 1-3 Brownlow Street, Liverpool L69 3GL, UK}

Corresponding author:

Christopher M Halloran

\section{” halloran@liverpool.ac.uk}

Associate Professor, Department of Surgery, Room 6-302 Victoria Building 1276 South Park Street Halifax, Canada B3H $2 Y 9$

Tel: 01517064087

Fax: 01517065826

\section{Introduction}

Adjuvant treatment following on from curative resection for pancreatic cancer has been in use for nearly thirty years and is still hotly debated. The treatments discussed in this review are centered on adjuvant chemoradiotherapy, combinations of biological agents with chemotherapy and combination chemotherapy with chemoradiotherapy.

\section{Adjuvant Chemoradiotherapy}

Clinical studies from the 1970s and 1980s indicated that the survival rates increased in locally advanced pancreatic cancer when treated with external beam radiotherapy (EBRT) with a radiation sensitizer [1, 2]. This led to the Gastrointestinal Tumor Study Group Trial 9173 trial in which patients who had had resection were randomized to either chemoradiotherapy, comprising 40 Gy EBRT with 5-fluorouracil (5-FU) and follow on 5-FU for six months, or no adjuvant treatment [3]. This trial planned to recruit 150 patients, but closed after 8 years, having only recruited 43 patients. The analysis showed an apparent improved survival in the treatment group compared to the control group (Table 1). A similar survival was seen in another 30 non-randomized patients registered to the treatment group [4]. Several subsequent studies showed that post-operative chemoradiation was feasible but the true survival benefit remained uncertain because none were randomized [5-7].

An European Organisation for Research and Treatment of Cancer (EORTC) trial randomized patients with various types of pancreatic cancers following resection to either chemoradiotherapy, 
Table 1 Summary of the findings from the main studies examining the effect of adjuvant chemo radiotherapy in pancreatic cancer.

\begin{tabular}{|c|c|c|c|c|c|c|c|}
\hline & & $\begin{array}{l}\text { Patient } \\
\text { Number }\end{array}$ & Regime & $\begin{array}{l}\text { Median } \\
\text { Survival } \\
\text { (Months) }\end{array}$ & $\begin{array}{c}\text { Two-year } \\
\text { survival } \\
\text { (\%) }\end{array}$ & $\begin{array}{l}\text { Three-year } \\
\text { survival } \\
\text { (\%) }\end{array}$ & $\begin{array}{c}\text { Five-year survival } \\
(\%)\end{array}$ \\
\hline \multirow{2}{*}{\multicolumn{2}{|c|}{$\begin{array}{c}\text { GITSG } 9173 \\
{[3]}\end{array}$}} & 21 & $\begin{array}{c}60 \text { Gy ERBT } \\
5-\mathrm{FU} \\
\text { Follow on 5-FU }\end{array}$ & 20 & 42 & - & $18^{*}$ \\
\hline & & 22 & Surgery/Observation & 11 & 15 & - & $0^{*}$ \\
\hline \multicolumn{2}{|c|}{$\begin{array}{c}\text { GITSG (1987) } \\
{[4]}\end{array}$} & 30 & $\begin{array}{c}60 \text { Gy ERBT } \\
5-F U \\
\text { Follow on 5-FU }\end{array}$ & 18 & 46 & - & - \\
\hline \multirow{4}{*}{$\begin{array}{c}\text { EORTC } \\
{[8,9]}\end{array}$} & $\begin{array}{c}\text { PDAC } \\
\text { RR } 0.7(0.5-1.1)\end{array}$ & 60 & $\begin{array}{c}40 \text { Gy ERBT } \\
5-\mathrm{FU}\end{array}$ & 17.1 & 37 & - & 20 \\
\hline & $P=0.099$ & 54 & Surgery/Observation & 12.6 & 23 & - & 10 \\
\hline & $\begin{array}{c}\text { PERI- } \\
\text { AMPULLARY }\end{array}$ & 44 & $\begin{array}{l}40 \text { Gy ERBT } \\
5-\mathrm{FU}\end{array}$ & 39.5 & 70 & - & 38 \\
\hline & $\begin{array}{c}\text { RR } 0.9(0.5-1.6) \\
P=0.737\end{array}$ & 49 & Surgery/Observation & 40.1 & 64 & - & 36 \\
\hline
\end{tabular}

* Estimated

EBRT $=$ External beam Radio-Therapy

5 -FU=5-Fluorouracil.

PDAC $=$ Pancreatic Ductal Adenocarcinoma

comprising 40 Gy EBRT and 5-FU (but no follow on 5-FU), or to no adjuvant treatment [8]. The EORTC trial included 114 patients with pancreatic ductal adenocarcinoma of the head of the pancreas and 93 patients with peri-ampullary cancer. There was no survival benefit for chemoradiation (Table 1), which was confirmed on longer follow-up [9]. An earlier study from Norway had explored the role of adjuvant combination chemotherapy, completely omitting chemoradiotherapy [10]. In this trial 61 patients with pancreatic cancers (including 14 patients with periampullary cancers) were randomized to adjuvant combination chemotherapy comprising, 5-FU, doxorubicin and mitomycin- $\mathrm{C}$, following resection compared to resection alone. Although the median survival and two-year survival rates were increased in the treatment group, the overall long-term rate was unaffected.

Given these uncertainties, the European Study Group for Pancreatic Cancer (ESPAC) designed a trial that included a twoby-two factorial design plus a simpler pragmatic randomization to answer the basic questions of whether (1) adjuvant therapy provided a survival benefit, and (2) whether this survival benefit required the use of adjuvant chemoradiotherapy, adjuvant chemotherapy or a combination of these. The ESPAC-1 trial two-by-two factorial design randomized each patient twice: (1) to either chemotherapy with 5-FU and folinic acid (FA) for six months or no chemotherapy and (2) to either 5-FU based chemoradiotherapy or no chemoradiotherapy [11]. The ESPAC1 plus pragmatic design randomized patients, by individual treatment group, to either (1) chemotherapy with 5-FU/FA for six months or no chemotherapy or (2) to either 5-FU based chemoradiotherapy or no chemoradiotherapy [12]. There were 289 patients randomized into the two-by-two factorial design [11] and a further 252 patients in the single option randomization study giving a total of 541 patients randomized in ESPAC-1 plus [12], from 83 clinicians in 61 cancer centres in 11 countries, thus making it, at the time, the largest adjuvant therapy trial in pancreatic cancer ever to be completed.. The intention to treat analysis showed no survival benefit from chemoradiotherapy but an improvement in five-year survival from around $8 \%$ for resection alone to $21 \%$ for resection plus adjuvant chemotherapy (Table 2).

The Radiation Therapy Oncology Group (RTOG)-9704 study comprised 538 patients with pancreatic cancer all given adjuvant 5-FU-based chemoradiation that were randomized to 3 weeks pre-chemoradiation and 12 weeks post-chemoradiation with either gemcitabine or to continuous infusion 5-FU $[13,14]$. The design of this study explored two types of add-on chemotherapy (5-FU or gemcitabine) to a 5-FU based chemoradiation backbone. The analysis was not by intention to treat such that only 451 of the 538 patients randomized were analysed, with another analysis on the 388 patients who had adenocarcinoma in the head of the pancreas. Overall, there were no survival differences between the two main treatment arms or subgroups (Table 3).

The EORTC 40013/FFCD/GERCOR phase II trial by Van Laethem et al. randomised 90 patients with an $\mathrm{RO}$ resection to receive four cycles of gemcitabine chemotherapy, or to combined chemoradiotherapy comprising two courses of gemcitabine followed by 50.4 Gy EBRT with concurrent weekly gemcitabine for 5-6 weeks [15]. Toxicity was comparable between the two arms as well as overall median survival and disease free survival. Local relapse rates were lower in the chemoradiotherapy arm ( $11 \%$ versus $24 \%$ respectively), though there was no difference in distant metastases ( $42 \%$ versus $40 \%$ respectively).

The additions of interferon-based protocols have been investigated in several studies but are associated with some improvement in survival but at a cost of significant toxicity. Linehan et al. undertook a single-centre, single-arm phase II study of 53 patients with resected pancreatic cancer received six weeks of EBRT 50.4 Gy with continuous infusion 5-FU, weekly 
Table 2 Summary of the ESPAC-1 data.

\begin{tabular}{|c|c|c|c|c|}
\hline & Modality & $\begin{array}{l}\text { Median Survival } \\
\text { (Months) }\end{array}$ & $\begin{array}{l}2 \text { Year Survival } \\
\text { (\%) }\end{array}$ & $\begin{array}{c}5 \text { Year Survival } \\
\text { (\%) }\end{array}$ \\
\hline $\begin{array}{l}\text { ESPAC-1 } \\
2 \times 2\end{array}$ & $\begin{array}{c}\text { Chemo radiotherapy } \\
\text { vs }\end{array}$ & 15.9 & 28.5 & 10 \\
\hline $\begin{array}{c}\text { Final analysis } \\
{[12]}\end{array}$ & No Chemo radiotherapy & 17.9 & 41.4 & $\begin{array}{c}19.6 \\
(p=0.053)\end{array}$ \\
\hline \multirow[t]{3}{*}{$\begin{array}{c}\text { ESPAC-1 } 2 \times 2 \\
\text { Final analysis } \\
{[12]}\end{array}$} & $\begin{array}{c}\text { Chemotherapy } \\
\text { vs }\end{array}$ & 20.1 & 39.7 & 21.1 \\
\hline & No Chemotherapy & 15.5 & 30 & $\begin{array}{c}8.4 \\
(p=0.009)\end{array}$ \\
\hline & $\begin{array}{l}\text { Observation } \\
\text { vs }\end{array}$ & 16.9 & 38.7 & 10.7 \\
\hline \multirow[t]{3}{*}{$\begin{array}{c}\text { ESPAC-1 } \\
\text { Individual groups } \\
{[12]}\end{array}$} & $\begin{array}{c}\text { Chemo radiotherapy } \\
\text { vs }\end{array}$ & 13.9 & 21.7 & 7.3 \\
\hline & $\begin{array}{c}\text { Chemotherapy } \\
\text { Vs }\end{array}$ & 21.6 & 44 & $\begin{array}{c}29 \\
(p=0.0005)\end{array}$ \\
\hline & $\begin{array}{l}\text { Chemo radiotherapy plus } \\
\text { follow on Chemotherapy }\end{array}$ & 19.9 & 35 & 13.2 \\
\hline \multirow[t]{2}{*}{$\begin{array}{c}\text { Composite data } \\
\text { ESPAC-1plus and } 3 \text { (v1) } \\
\text { [35] }\end{array}$} & 5-FU / FA* & 23.2 & 49 & 24 \\
\hline & Observation & 16.8 & 37 & 14 \\
\hline
\end{tabular}

5-FU=5-Fluorouracil. FA = Folinic Acid

*HR 0.70, $\mathrm{Cl}(0.55-0.88) ; \mathrm{p}=0.003$

Table 3 Summary of randomised trials examining the effect of gemcitabine based chemoradiation.

\begin{tabular}{|c|c|c|c|c|c|}
\hline & $\begin{array}{l}\text { Patient } \\
\text { Number }\end{array}$ & Regime & $\begin{array}{l}\text { Median } \\
\text { Survival } \\
\text { (Months) }\end{array}$ & $\begin{array}{l}\text { Two-year } \\
\text { survival } \\
\text { (\%) }\end{array}$ & $\begin{array}{l}\text { Three-year survival } \\
\text { (\%) }\end{array}$ \\
\hline & 45 & 4 cycles Gemcitabine & 24.4 & 50.2 & - \\
\hline $\begin{array}{c}\text { EORTC } 40013 \\
{[15]}\end{array}$ & 45 & $\begin{array}{c}2 \text { cycles Gemcitabine } \\
+ \\
\begin{array}{c}\text { Gemcitabine and } 50.5 \text { Gy } \\
\text { EBRT }\end{array}\end{array}$ & 24.3 & 50.6 & - \\
\hline \multirow{2}{*}{$\begin{array}{c}\text { RTOG-9704 } \\
{[13,14]} \\
\text { Head of pancreas } \\
\text { only, eligible = } \\
388\end{array}$} & 187 & $\begin{array}{l}\text { Gemcitabine pre- } \\
\text { Chemoradiotherapy, } \\
50.4 \text { Gy EBRT + 5-FU, } \\
\text { Gemcitabine post- } \\
\text { Chemoradiotherapy } \\
\text { vs }\end{array}$ & $\begin{array}{c}20.5^{*} \\
(p=0.09)\end{array}$ & - & 31 \\
\hline & 201 & $\begin{array}{c}\text { 5-FU pre- } \\
\text { Chemoradiotherapy, } \\
\text { 50.4 Gy EBRT + 5-FU, } \\
\text { 5-FU post- } \\
\text { Chemoradiotherapy }\end{array}$ & 16.9 & - & 22 \\
\hline
\end{tabular}

*HR=0.82 (0.65-1.03); P=0.09

EBRT - External Beam Radiotherapy

$5 F U$ - 5-fluorouracil

intravenous bolus cisplatin and interferon- $\alpha$ subcutaneously 3 times per week followed by two 4-week cycles of gemcitabine [16]. Sixteen patients (30\%) failed to complete adjuvant therapy, due to: disease progression ( 7 patients), toxicity ( 7 patients), and consent withdrawal ( 2 patients). No patients completed planned therapy. The median overall survival was 25 months [16]. The American College of Surgeons Oncology Group Z05031 multicentre phase II trial aimed to recruit 93 patients with resected pancreatic head cancer also treated with six weeks of EBRT 50.4 Gy and continuous infusion 5-FU, weekly intravenous bolus cisplatin and interferon- $\alpha$ subcutaneously 3 times per week followed on this occasion by two 6-week courses of continuous infusion 5-FU [17]. The high rates of grades 3 and 4 toxic effects (95\%) resulted in closure of the trial after 89 patients had been recruited. The median survival was calculated on only 80 of the patients and this was 25.4 months [18]. 
The multicentre phase III CapRI trial randomized 132 resected pancreatic cancer patients to receive either adjuvant chemo radiotherapy with six weeks of EBRT $50.4 \mathrm{~Gy}$ with a continuous infusion 5-FU, weekly intravenous bolus cisplatin and interferon- $\alpha$ subcutaneously 3 times per week followed by two 6-week courses of continuous infusion 5-FU $(n=64)$ or bolus injections of 5-FU/FA for six cycles $(n=68)$ [18]. Eighty-five percent of patients in the chemoradiotherapy arm and $16 \%$ of patients in the 5-FU/FA arm had grade 3 or 4 toxicity. The median survival was 26.5 months and 28.5 months respectively (Table 4).

The ECOG 2204 phase II trial randomised 137 (129 eligible) patients with resected pancreatic cancer to receive either cetuximab plus gemcitabine before chemo radiotherapy of $50.4 \mathrm{~Gy}$ with capecitabine follwed by cetuximab plus gemcitabine $(n=67)$ or bevacuzimab plus gemcitabine before chemo radiotherapy of $50.4 \mathrm{~Gy}$ with capecitabine follwed by bevacuzimab plus gemcitabine $(n=62)$ [19]. The two-year survival was $35 \%$ and $37 \%$ resepctively and over $10 \%$ of patients suffered disease reoccurance during adjuvant treatment [19] (Table 4).

The PACT-7 phase II trial randomized 102 patients with resected pancreatic cancer to either cisplatin, epirubicin, 5-FU, gemcitabine (PEFG) or gemcitabine every 4 weeks for 3 months and followed by followed by chemoradiation with continuous infusion of 5-FU. The combination chemotherapy group had a non-significant survival improvement and more haematological toxicity [20] (Table 4).

The RTOG 0848 phase III factorial-designed trial commenced recruitment in 2009 aiming to randomize 950 patients with resected pancreatic head cancer to adjuvant gemcitabine versus gemcitabine with erlotinib. After 5 cycles of gemcitabine those patients with no progression would then be randomised to concurrent fluoropyrimidine treatment and radiotherapy or continue with adjuvant gemcitabine based chemotherapy. In February 2014 after 378 patients had been recruited the erlotinib arm was closed to further recruitment because there was no evidence of benefit. The EORTC protocol 40084-22084 follows the RTOG 0848 protocol [21].

The CapRI-2 trial (phase II) was launched in 2008 with a view to randomise 135 patients to one of three arms [22]. The first arm involves radiotherapy (3-D conformal or intensity modulated) with cisplatin and interferon- $\alpha-2 b$, and 3 cycles of 5-FU chemotherapy, the second arm excludes cisplatin from the treatment schedule and the third arm excludes cisplatin and radiotherapy. It hypothesises that de-escalation of the CapRI regime is likely to reduce toxicity, with minimal impact on clinical response.

Algenpantucel-L is an immunotherapy comprising irradiated live allogenic human pancreatic cancer HAPa-1 and HAPa2cell lines 2 genetically modified to express cell surface alphagal carbohydrates. In a phase II trial of 70 patients the median disease free survival was 14.1 months when used in combination with gemcitabine plus 5-FU based chemo radiotherapy $[23,24]$. A phase III trial which commenced in May 2010 which plans to recruit 722 patients and passed its first safety meeting in March 2014 after 222 patients had been randomised [25].

\section{Aduvant Chemotherapy}

ESPAC-1 provided evidence that adjuvant chemotherapy improves survival compared to resection without chemotherapy (Table 2). The survival benefit of chemotherapy was evident in resection margin positive (R1) as well as resection margin negative (R0) patients. A meta-analysis of all adjuvant chemotherapy trials showed a death reduction in patients with resected pancreatic cancers of $25 \%$ [26] with a survival advantage of post-resectional chemotherapy in those patients with an RO margin over those with an R1 margin [27]. Adjuvant chemotherapy has been shown not to affect the improved quality of life following resection alone [28].

The CONKO-001 randomized phase III trial compared gemcitabine, which had been shown to have some advantages over 5-FU in the advanced setting [29], to observation alone following resection of pancreatic cancer [30]. Median disease free survival for the gemcitabine group was 13.4 months, significantly longer when compared to 6.9 months for the observation arm. The estimated disease free survival at 3 and 5 years was $23.5 \%$ and $16.5 \%$ in the gemcitabine group vs. $7.5 \%$ and $5.5 \%$ in the observation group, respectively. With longer term follow-up a significantly improved overall median survival in the gemcitabine arm of 22.8 months was also shown, versus 20.2 months in the observation arm [31] . Studies from Japan have also supported a role for gemcitabine in the adjuvant setting [32,33] (Table 5).

The ESPAC-3 trial initially compared resection alone with adjuvant 5-FU/FA as in ESPAC-1plus [11, 12] and also with gemcitabine based on results from the advanced cancer setting [29]. With the subsequent final results of the two-by-two factorial trial of ESPAC-1 [12] this was modified to ESPAC3 (v2) with only two arms randomizing 1088 patients to either 5-FU/FA or gemcitabine. Gemcitabine did not have an improved survival advantage of over 5-FU/FA but had a better toxicity profile [34]. By combining the data form ESPAC-1plus and the data from the initial threearmed ESPAC-3 trial it was also possible to comfirm the survival advantage of 5-FU/FA compared to resection alone (Table 5) [35].

ESPAC-3 data have been evaluated to determine the optimal duration and time to initiate chemotherapy [36]. They concluded that completion of all 6 cycles of chemotherapy was an independent prognostic factor after resection for pancreatic adenocarcinoma and there was no survival disadvantage identified from delaying initiation of chemotherapy for up to 12 weeks, thus allowing adequate time for postoperative recovery [36]. Using blinded analysis of tissue microarrays from 434 patients randomized to chemotherapy in the ESPAC-3 trial plus true controls from ESPAC- 1 and ESPAC-3, it was shown that hENT1 (human equilibrative nucleoside transporter 1) expression using the 10D7G2 anti-hENT1 antibody for immunohistochemistry has the potential for greatly increased survival when using adjuvant gemcitabine in patients with a low hENT-1 levels and 5-FU/FA in those with high levels [37].

The JASPAC-01 phase III trial randomized 385 patients in Japan to receive either gemcitabine or S-1 an orally active fluoropyrimidine [38] . S-1 contains a prodrug of 5-FU (tegafur) along with two other agents designed to minimize gastrointestinal and systemic toxicity (gimerecil and oteracil) effectively increasing the tolerable tumor dose of 5-FU. The two-year survival for S-1 was $70 \%$, significantly greater when compared to $53 \%$ for gemcitabine. Adjuvant S-1 therapy will need to be investigated in western patients with pancreatic 
Table 4 Summary of the findings from randomized studies examining the effect of combination biological adjuvant chemo radiotherapy .

\begin{tabular}{|c|c|c|c|c|}
\hline & Patient Number & Regime & $\begin{array}{l}\text { Median Survival } \\
\text { (Months) }\end{array}$ & $\begin{array}{c}\text { Two-year survival } \\
\text { (\%) }\end{array}$ \\
\hline \multirow{2}{*}{$\begin{array}{c}\text { ECOG-2204 } \\
{[19]}\end{array}$} & 67 & $\begin{array}{l}\text { Cetuximab+ Gemcitabine pre- } \\
\text { Chemoradiotherapy, } \\
50.4 \mathrm{~Gy}+\text { Capecitabine } \\
\text { Chemoradiotherapy } \\
\text { Cetuximab+Gemcitabine post- } \\
\text { Chemoradiotherapy } \\
\text { vs }\end{array}$ & - & 35 \\
\hline & 62 & $\begin{array}{l}\text { Bevacuzimab+ Gemcitabine } \\
\text { pre- Chemoradiotherapy, } \\
50.4 G y+\text { capecitabine } \\
\text { Chemoradiotherapy } \\
\text { Bevacuzimab+ Gemcitabine } \\
\text { post- Chemoradiotherapy }\end{array}$ & - & 37 \\
\hline \multirow[t]{2}{*}{$\begin{array}{c}\text { CapRI } \\
\text { [18] }\end{array}$} & 53 & $\begin{array}{c}\text { 5-FU+CP+iFN } \alpha 2 \mathrm{~b} \\
\text { Chemoradiotherapy } \\
+ \\
2 \text { cycles of } 5 \text {-FU } \\
\text { post- Chemoradiotherapy } \\
\text { vs }\end{array}$ & $32.1 *$ & - \\
\hline & 57 & 6 cycles of 5 -FU/FA & 28.5 & - \\
\hline \multirow{2}{*}{$\begin{array}{l}\text { PACT-7 } \\
{[20]}\end{array}$} & 51 & $\begin{array}{c}\text { Gemcitabine } 3 \text { months } \\
+ \\
\text { 5-FU or capecitabine } \\
\text { Chemoradiotherapy } \\
\text { vs }\end{array}$ & 24.8 & - \\
\hline & 49 & $\begin{array}{c}\text { PEFG } 3 \text { months } \\
+ \\
\text { 5-FU or capecitabine } \\
\text { Chemoradiotherapy }\end{array}$ & 28.9 & - \\
\hline
\end{tabular}

$H R=1.2(0.49-2.95) ; p=0.49$

5 -FU=5-Fluorouracil.

PEFG = cisplatin, epirubicin, 5-FU, gemcitabine

cancer as their toxicity profile is quite different to patients from Japan and other parts of Asia (Table 5).

A recent network meta-analysis has shown that the best survival results are achieved with either adjuvant 5-FU or gemcitabine chemotherapy reducing mortality after surgery by about a third whilst chemoradiation plus chemotherapy is less effective in prolonging survival and is more toxic than chemotherapy [39]. The evidence now suggests that older and relatively ineffective chemotherapy combinations should be discarded $[10,40,41]$ (Table 6), whereas regimens using 5-FU/FA, gemcitabine or S-1 will be the platforms for future development of adjuvant therapies [42]. In a multicentre, non-randomized phase II study, 76 patients with resected pancreatic cancer received gemcitabine and cetuximab with a median disease free survival of 10 months and a median overall survival of 22.4 months. It was concluded that the addition of cetuximab to adjuvant gemcitabine did not appear to improve survival [43]. Another phase II trial used fixed dose gemcitabine plus erlotinib in 25 patients with $\mathrm{R} 0$ resection for 4 months, followed by 8 months of erlotinib with a median recurrence free survival of 14 months [44].

Based on successes in the advanced pancreatic cancer setting current ongoing adjuvant trials are comparing gemcitabine with gemcitabine and capecitabine $[45,46]$ in ESPAC-4, and adjuvant gemcitabine / capecitabine / hypothermia in the phase III Hypothermia European Adjuvant Trial (HEAT Trial) [47]. The phase II/III trial PACT 15 is evaluating adjuvant cisplatin, epirubicin, capecitabine and gemcitabine (PEXG) versus adjuvant gemcitabine versus neoadjuvant plus adjuvant PEXG [48]. The study opened in 2010 and an estimated 370 patients are planned to be recruited. CONKO-005 will investigate the effect of adjuvant erlotinib plus gemcitabine versus gemcitabine alone [49]. A combination of FA, 5-FU, irinotecan and oxaliplatin (FOLFIRINOX) [50] is being tested in both the adjuvant and neoadjuvant settings [51] and the APACT study which opened in March 2014 is testing adjuvant albumin bound paclitaxel (Abraxane) [52] plus gemcitabine against gemcitabine alone [53].

\section{Conclusions}

The understanding of pancreatic cancer biology progresses [54,55], providing earlier opportunities for treatment [56]. The current data interpretation strongly supports the continued use of adjuvant systemic chemotherapy with either 5-FU and FA or gemcitabine following curative resection for pancreatic adenocarcinoma. Gemcitabine has the added advantage of lesser 
Table 5 Gemcitabine based adjuvant chemotherapy in pancreatic cancer.

\begin{tabular}{|c|c|c|c|c|c|c|c|}
\hline & Patient Number & Regime & $\begin{array}{l}\text { Median Survival } \\
\text { (Months) }\end{array}$ & $\begin{array}{c}\text { One-year } \\
\text { Survival } \\
\text { (\%) }\end{array}$ & $\begin{array}{c}\text { Two-year } \\
\text { survival } \\
\text { (\%) }\end{array}$ & $\begin{array}{c}\text { Three-year } \\
\text { survival } \\
\text { (\%) }\end{array}$ & $\begin{array}{c}\text { Five-year } \\
\text { survival } \\
\text { (\%) }\end{array}$ \\
\hline \multirow[b]{2}{*}{$\begin{array}{c}\text { CONKO-001 } \\
{[30,31]}\end{array}$} & 179 & Gemcitabine & 22.1 & 72.5 & 47.5 & 34 & 22.5 \\
\hline & 175 & $\begin{array}{l}\text { Surgery / } \\
\text { Observation }\end{array}$ & 20.2 & 72.5 & 42 & 20.5 & 11.5 \\
\hline \multirow[b]{2}{*}{$\begin{array}{c}\text { Yoshitomi et al } \\
{[33]}\end{array}$} & 50 & Gemcitabine & 29.8 & 85.7 & - & 46.9 & - \\
\hline & 50 & $\begin{array}{l}\text { Gemcitabine + } \\
\text { Uracil/tegafur }\end{array}$ & $\begin{array}{c}21.2 \\
(p=0.28)\end{array}$ & 80 & - & 30.4 & - \\
\hline \multirow{2}{*}{$\begin{array}{l}\text { JSAP02 } \\
{[32]}\end{array}$} & 58 & Gemcitabine & 22.3 & 77.6 & 48.5 & - & 23.9 \\
\hline & 60 & Surgery alone & $18.4^{*}$ & 75 & 40 & - & 10.6 \\
\hline \multirow[t]{2}{*}{$\begin{array}{c}\text { ESPAC-3(v2) } \\
{[34]}\end{array}$} & 537 & Gemcitabine & $\begin{array}{c}23.6 \\
(p=0.39)\end{array}$ & 80.1 & 49.1 & - & - \\
\hline & 551 & 5-FU / FA & 23 & 78.5 & 48.1 & - & - \\
\hline \multirow{2}{*}{$\begin{array}{c}\text { JASPAC } 01 \\
\text { [38] }\end{array}$} & 191 & Gemcitabine & 25.5 & - & 53 & - & - \\
\hline & 187 & S-1 & $46.3^{* *}$ & - & $70 * * *$ & - & - \\
\hline
\end{tabular}

$* H R=0.77(0.51-1.14) ; p=0.19$

$* * P<0.0001$ vs gemcitabine

$* * * H R=0.56(042-0.74) ; P<0.0001$

5 -FU=5-Fluorouracil

FA = Folinic Acid

Table 6 Comparison of randomised trials using combination chemotherapy for resected pancreatic cancer.

\begin{tabular}{|c|c|c|c|c|c|c|}
\hline & $\begin{array}{l}\text { Patient } \\
\text { Number }\end{array}$ & Regime & $\begin{array}{l}\text { Median } \\
\text { Survival } \\
\text { (Months) }\end{array}$ & $\begin{array}{l}\text { Two-year } \\
\text { survival } \\
\text { (\%) }\end{array}$ & $\begin{array}{l}\text { Three-year } \\
\text { survival } \\
\text { (\%) }\end{array}$ & $\begin{array}{c}\text { Five-year survival } \\
\text { (\%) }\end{array}$ \\
\hline \multirow[t]{2}{*}{$\begin{array}{c}\text { Bakkevold et al } \\
{[10]}\end{array}$} & 30 & $\begin{array}{c}\text { 5-FU } \\
\text { Doxorubicin } \\
\text { Mitomycin-C }\end{array}$ & $\begin{array}{c}23 \\
(p=0.02)\end{array}$ & 70 & 27 & 4 \\
\hline & 31 & Observation & 11 & 45 & 30 & 8 \\
\hline \multirow{2}{*}{$\begin{array}{c}\text { Takada et al } \\
{[40]}\end{array}$} & 81 & $\begin{array}{c}\text { 5-FU } \\
\text { Mitomycin-C }\end{array}$ & - & - & - & 11.5 \\
\hline & 77 & Observation & - & - & - & 18 \\
\hline \multirow{2}{*}{$\begin{array}{c}\text { Kosuge et al } \\
{[41]}\end{array}$} & 45 & $\begin{array}{c}\text { 5-FU } \\
\text { Cisplatin }\end{array}$ & 12.5 & - & - & 26.4 \\
\hline & 44 & Observation & 15.8 & - & - & $\begin{array}{c}14.9 \\
(p=0.94)\end{array}$ \\
\hline
\end{tabular}

5-FU=5-Fluorouracil

$\mathrm{FA}=$ Folinic Acid.

*Disease free survival, $\mathrm{p}<0.001$

** HR 0.70, $\mathrm{Cl}(0.55-0.88) ; \mathrm{p}=0.003$

toxicity than 5-FU, and is therefore recommended as the first line adjuvant chemotherapy agent. Adjuvant S-1 looks promising, whilst stratified medicine using predictive biomarkers such as
hENT1 also need further evaluation. To date there are no studies which provide sufficient evidence to support the use of adjuvant chemoradiation, however its role in neoadjuvant therapies, is currently under investigation [57]. 


\section{Reference}

1 Gastrointestinal tumour study group (1979) Multi-Institutional Comparitive Trial of Radiation Therapy Alone and in Combination with 5-flurouracil for Locally Unresectable Pancreatic Carcinoma. Annals of Surgery 189: 205-208.

2 Moertel CG, Frytak S, Hahn RG, Connell MJ, Reitemeier RJ, et al. (1981) Therapy of locally unresectable pancreatic carcinoma:A randomized comparison of high dose (6000 rads) radiation alone, moderate dose radiation (4000 rads+ 5-fluorouracil), and high dose radiation+ 5-fluorouracil. The gastrointestinal tumor study group. Cancer 48: 1705-1710.

3 Kalser MH, Ellenberg SS (1985) Pancreatic cancer. Adjuvant combined radiation and chemotherapy following curative resection. Arch Surg 120: 899-903.

4 Gastrointestinal Tumour Study Group (1987) Further evidence of effective adjuvant combined radiation and chemotherapy following curative resection of pancreatic cancer. Cancer 59: 2006-2010.

5 Conlon KC, Klimstra DS Brennan MF (1996) Long-term survival after curative resection for pancreatic ductal adenocarcinoma. Clinicopathologic analysis of 5-year survivors. Annals of Surgery 223: 273-279.

6 Neoptolemos JP (1998) Adjuvant radiotherapy and follow-on chemotherapy in patients with pancreatic cancer: results of the UK Pancreatic Cancer Study Group (UKPACA-1). Gastrointestinal Cancer 2: 235-245.

7 Yeo CJ, Abrams R, Grochow L, Sohn TA, Ord SE, et al. (1998) Pancreaticoduodenectomy for pancreatic adenocarcinoma: postoperative adjuvant chemoradiation improves survival: a prospective, single-institution experience. Annals of Surgery 225: 621-633.

8 Klinkenbijl JH, Jeekel J, Sahmoud T, Van Pel R, Couvreur M, et al. (1999) Adjuvant radiotherapy and 5-fluorouracil after curative resection of cancer of the pancreas and periampulliary region. A phase III trial of the EORTC gastrointestinal tract cancer cooperative group. Annals of Surgery 230: 776-784.

9 9.Smeenk HG, van Eijck CH, Hop WC, Erdmann J, Tran KC, et al. (2007) Long-term survival and metastatic pattern of pancreatic and periampullary cancer after adjuvant chemoradiation or observation: long-term results of EORTC trial 40891. Ann Surg 246: 734-740.

10 Bakkevold KE, Arnesjo B, Dahl O, Kambestad B (1993) Adjuvant combination chemotherapy (AMF) following radical resection of carcinoma of the pancreas and papilla of Vater-results of a controlled, prospective, randomised multicentre study. European Journal of Cancer 29: 698-703.

11 Neoptolemos JP1, Dunn JA, Stocken DD, Almond J, Link K, et al. (2001) Adjuvant chemoradiotherapy and chemotherapy in resectable pancreatic cancer: a randomised controlled trial. Lancet 358: 15761585.

12 Neoptolemos JP1, Stocken DD, Friess H, Bassi C, Dunn JA, et al. (2004) A randomized trial of chemoradiotherapy and chemotherapy after resection of pancreatic cancer. N Engl J Med 350: 1200-1210.

13 Regine WF, Winter KA, Abrams RA, Safran H, Hoffman JP, et al. (2008) Fluorouracil vs gemcitabine chemotherapy before and after fluorouracil-based chemoradiation following resection of pancreatic adenocarcinoma: a randomized controlled trial. Journal of the American Medical Association 299: 1019-1026.
14 Regine WF, Winter KA, Abrams RA, Safran H, Hoffman JP et al. (2011) Fluorouracil-based chemoradiation with either gemcitabine or fluorouracil chemotherapy after resection of pancreatic adenocarcinoma: 5-year analysis of the US Intergroup/RTOG 9704 phase III trial. Annals of Surgical Oncology 18: 1319-1326.

15 Van Laethem JL, Hammel P, Mornex F, Azria D, Van Tienhoven G, et al. (2010) Adjuvant gemcitabine alone versus gemcitabine-based chemoradiotherapy after curative resection for pancreatic cancer: a randomized EORTC-40013-22012/FFCD-9203/GERCOR phase II study. Journal of Clinical Oncology 28: 4450-4456.

16 Linehan DC, Tan MCB, Strasberg SM, Drebin JA, Hawkins WG, et al. (2008) Adjuvant interferon-based chemoradiation followed by gemcitabine for resected pancreatic adenocarcinoma: a singleinstitution phase II study. Annals of Surgery 248: 145-151.

17 Picozzi VJ, Abrams RA, Decker PA, Traverso W, Reilly EM et al. (2011) Multicenter phase II trial of adjuvant therapy for resected pancreatic cancer using cisplatin, 5-fluorouracil, and interferon-alfa-2b-based chemoradiation: ACOSOG Trial Z05031. Annals of Oncology 22: 348354.

18 Schmidt J, Abel U, Debus J, Harig S, Hoffmann K, et al. (2012) Open-Label, Multicenter, Randomized Phase III Trial of Adjuvant Chemoradiation Plus Interferon Alfa-2b Versus Fluorouracil and Folinic Acid for Patients With Resected Pancreatic Adenocarcinoma. Journal of Clinical Oncology 30: 4077-4083.

19 Berlin J, Catalano PJ, Feng Y, Lowy AM, Blackstock AW, et al. (2010) ECOG 2204: An intergroup randomized phase II study of cetuximab (Ce) or bevacizumab (B) in combination with gemcitabine (G) and in combination with capecitabine (Ca) and radiation (XRT) as adjuvant therapy (Adj Tx) for patients (pts) with completely resected pancreatic adenocarcinoma (PC). Journal of Clinical Oncology 28: 4034.

20 Reni M1, Balzano G, Aprile G, Cereda S, Passoni P, et al. (2012) Adjuvant PEFG (cisplatin, epirubicin, 5-fluorouracil, gemcitabine) or gemcitabine followed by chemoradiation in pancreatic cancer: a randomized phase II trial. Ann Surg Oncol 19: 2256-2263.

21 http://www.rtog.org/ClinicalTrials/ProtocolTable/StudyDetails. aspx?study $=0848$

22 Marten A1, Schmidt J, Ose J, Harig S, Abel U, et al. (2009) A randomized multicentre phase II trial comparing adjuvant therapy in patients with interferon alpha-2b and 5-FU alone or in combination with either external radiation treatment and cisplatin (CapRI) or radiation alone regarding event-free survival - CapRI-2. BMC Cancer 9: 160 .

23 Hardacre JM, Mulcahy MF, Small Jr W, Talamonti M, Obel JC, et al. (2011) Effect of the addition of algenpantucel-L immunotherapy to standard adjuvant therapy on survival in patients with resected pancreas cancer. Journal of Clinical Oncology 29: 236.

24 Hardacre JM, Mulcahy M, Small W, Talamonti M, Obel J, et al. (2013) Addition of algenpantucel-L immunotherapy to standard adjuvant therapy for pancreatic cancer: a phase 2 study. J Gastrointest Surg 17: 94-100.

25 Watson S1, Woodside JV, Ware LJ, Hunter SJ, McGrath A, et al. (2015) Effect of a Web-Based Behavior Change Program on Weight Loss and Cardiovascular Risk Factors in Overweight and Obese Adults at High Risk of Developing Cardiovascular Disease: Randomized Controlled Trial. J Med Internet Res 17: e177.

26 Stocken DD1, Bachler MW, Dervenis C, Bassi C, Jeekel H, et al. (2005) Meta-analysis of randomised adjuvant therapy trials for pancreatic cancer. Br J Cancer 92: 1372-1381. 
27 Butturini G, Stocken DD, Wente MN, Jeekel H, Klinkenbijl JH, et al. (2008) Influence of resection margins and treatment on survival in patients with pancreatic cancer: meta-analysis of randomized controlled trials. Arch Surg 143: 75-83.

28 Carter R, Stocken DD, Ghaneh P, Bramhall SR, Olah A, et al. (2009) European Study Group for Pancreatic Cancer (ESPAC). Longitudinal quality of life data can provide insights on the impact of adjuvant treatment for pancreatic cancer-Subset analysis of the ESPAC-1 data. International Journal of Cancer 124: 2960-2965.

29 Burris HA, Moore MJ, Andersen J, Green MR, Rothenberg ML, et al. (1997) Improvements in survival and clinical benefit with gemcitabine as first-line therapy for patients with advanced pancreas cancer: a randomized trial. J Clin Oncol 15: 2403-2413.

30 Oettle H, Post S, Neuhaus P, Gellert K, Langrehr J, et al. (2007) Adjuvant chemotherapy with gemcitabine vs observation in patients undergoing curative-intent resection of pancreatic cancer: a randomized controlled trial. Journal of the American Medical Association 297: 267-277.

31 Oettle H, Neuhaus P, Hochhaus A, Hartmann JT, Gellert K, et al. (2013) Adjuvant chemotherapy with gemcitabine and long-term outcomes among patients with resected pancreatic cancer: the CONKO-001 randomized trial. JAMA 310: 1473-1481.

32 Ueno H, Kosuge T, Matsuyama Y, Yamamoto J, Nakao A, et al. (2009) $A$ randomised phase III trial comparing gemcitabine with surgeryonly in patients with resected pancreatic cancer: Japanese Study Group of Adjuvant Therapy for Pancreatic Cancer. British Journal of Cancer 101: 908-915.

33 Yoshitomi $H$, Togawa A, Kimura F, Ito $H$, Shimizu $H$, et al. (2008) A randomized phase II trial of adjuvant chemotherapy with uracil/ tegafur and gemcitabine versus gemcitabine alone in patients with resected pancreatic cancer. Cancer 113: 2448-2456.

34 Neoptolemos JP, Stocken DD, Bassi C, Ghaneh P, Cunningham D, et al. (2010) Adjuvant chemotherapy with fluorouracil plus folinic acid vs gemcitabine following pancreatic cancer resection: a randomized controlled trial. Journal of the American Medical Association 304: 1073-1081.

35 Neoptolemos JP, Stocken DD, Tudur Smith C, Bassi C, Ghaneh P, et al. (2009) Adjuvant 5-fluorouracil and folinic acid vs observation for pancreatic cancer: composite data from the ESPAC-1 and $-3(v 1)$ trials. Br J Cancer 100: 246-250.

36 Valle JW, Palmer D, Jackson R, Cox T, Neoptolemos JP, et al. (2014) Optimal duration and timing of adjuvant chemotherapy after definitive surgery for ductal adenocarcinoma of the pancreas: ongoing lessons from the ESPAC-3 study. Journal of Clinical Oncology 32: 504-512.

37 Greenhalf W, Ghaneh P, Neoptolemos JP, Palmer DH, Cox TF, et al. (2014) Pancreatic cancer hENT1 expression and survival from gemcitabine in patients from the ESPAC-3 trial. J Natl Cancer Inst 106: djt347.

38 Fukutomi A, Uesaka K, Boku N, Kanemoto H, Konishi M, Matsumoto I, et al. (2013) JASPAC 01:Randomized phase III trial of adjuvant chemotherapy with gemcitabine versus S-1 for patients with resected pancreatic cancer. Journal of Clinical Oncology 31: 4008.

39 Liao WC1, Chien KL, Lin YL, Wu MS, Lin JT, et al. (2013) Adjuvant treatments for resected pancreatic adenocarcinoma: a systematic review and network meta-analysis. Lancet Oncol 14: 1095-1103.
40 Takada T1, Amano H, Yasuda H, Nimura Y, Matsushiro T, et al. (2002) Is postoperative adjuvant chemotherapy useful for gallbladder carcinoma? A phase III multicenter prospective randomized controlled trial in patients with resected pancreaticobiliary carcinoma. Cancer 95: 1685-1695.

41 Kosuge T, Kiuchi T, Mukai K, Kakizoe T (2006) A multicenter randomized controlled trial to evaluate the effect of adjuvant cisplatin and 5-fluorouracil therapy after curative resection in cases of pancreatic cancer. Japanese Journal of Clinical Oncology 36: 159165.

42 Neoptolemos JP, Cox TF (2013) Bayesian analysis unravels pancreascancer adjuvant therapy. Lancet Oncol 14: 1034-1035.

43 Fensterer $\mathrm{H}$, Schade-Brittinger $\mathrm{C}$, Maller $\mathrm{HH}$, Tebbe S, Fass J, et al. (2013) Multicenter phase II trial to investigate safety and efficacy of gemcitabine combined with cetuximab as adjuvant therapy in pancreatic cancer (ATIP). Ann Oncol 24: 2576-2581.

44 Bao PQ, Ramanathan RK, Krasinkas A, Bahary N, Lembersky BC, et al. (2011) Phase II study of gemcitabine and erlotinib as adjuvant therapy for patients with resected pancreatic cancer. Ann Surg Oncol 18: $1122-1129$.

45 Cunningham D, Chau I, Stocken DD, Valle JW, Smith D, et al. (2009) Phase III randomized comparison of gemcitabine versus gemcitabine plus capecitabine in patients with advanced pancreatic cancer. J Clin Oncol 27: 5513-5518.

46 Sultana A, Smith CT, Cunningham D, Starling N, Neoptolemos JP, et al. (2007) Meta-analyses of chemotherapy for locally advanced and metastatic pancreatic cancer. J Clin Oncol 25: 2607-2615.

47 http://clinicaltrials.gov/show/NCT01077427

48 http://clinicaltrials.gov/ct2/show/record/NCT01150630

49 http://apps.who.int/trialsearch/Trial2.aspx?TrialID=EUCTR2007003813-15-DE

50 Conroy T, Desseigne F, Ychou M, BouchÃC O, Guimbaud R, et al. (2011) FOLFIRINOX versus gemcitabine for metastatic pancreatic cancer. N Engl J Med 364: 1817-1825.

51 Dijkman BG, Busse JW, Walter SD, Bhandari M; TRUST Investigators (2011) The impact of clinical data on the evaluation of tibial fracture healing. Trials 12: 237.

52 Von Hoff DD, Ervin T, Arena FP, Chiorean EG, Infante J, et al. (2013) Increased survival in pancreatic cancer with nab-paclitaxel plus gemcitabine. N Engl J Med 369: 1691-1703.

53 http://clinicaltrials.gov/ct2/show/record/NCT01964430

54 Tuveson D, Hanahan D (2011) Translational medicine: Cancer lessons from mice to humans. Nature 471: 316-317.

55 PÃ@rez-Mancera PA1, Guerra C, Barbacid M, Tuveson DA (2012) What we have learned about pancreatic cancer from mouse models. Gastroenterology 142: 1079-1092.

56 Tuveson DA1, Neoptolemos JP (2012) Understanding metastasis in pancreatic cancer: a call for new clinical approaches. Cell 148: 21-23.

57 Roland CL1, Yang AD, Katz MH, Chatterjee D, Wang $H$, et al. (2015) Neoadjuvant therapy is associated with a reduced lymph node ratio in patients with potentially resectable pancreatic cancer. Ann Surg Oncol 22: 1168-1175. 